\title{
NAVIGATING THE PUBliCATION PROCESS: AN ASABE JOURNALS’ PERSPECTIVE
}

\author{
G. A. Fox, K. R. Douglas-Mankin, K. Muthukumarappan, J. Zhu, J. C. Walker
}

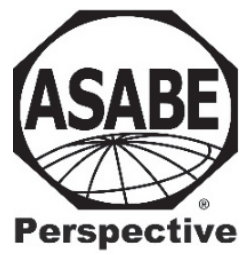

HighLIGHTS

- ASABE journals publish impactful research in multiple article types in addition to research articles.

- Prospective authors should consider a journal's peer-review quality, readership, metrics, and page charges.

- An article's impact should be measured based on citations instead of predicted based on the journal's impact factor.

- Always recommend subject matter experts as reviewers so that a manuscript can benefit from their suggestions.

- Publishing in ASABE journals offers opportunities for contributing to and being recognized by the profession.

Keywords. Impact factor, Page charges, Peer-reviewed journals, Review quality, Review time.

$\mathrm{T}$ The world of publishing has changed significantly in the last two decades. These changes include, but are not limited to: (1) the total numbers of scientific journals and manuscript submissions have increased exponentially; (2) new metrics, such as the journal impact factor (IF), have been developed and widely adopted in an attempt to quantify the relative prominence of publications (Callaway, 2016); (3) there has been a transition to commercial, for-profit publishers; and (4) as for-profit publishing has increased, many new journals have emerged that publish in an open-access environment. These trends have led to some publishers appearing to be solely focused on profit to the detriment of a high-quality peer-review process. At the same time, professional scientific and engineering societies, such as ASABE, have maintained their publication department and strive to compete with commercial, forprofit publishers.

Submitted for review in August 2019 as manuscript number EOPD 13648; approved for publication as an Invited Perspective by the Education, Outreach, \& Professional Development Community of ASABE in August 2019.

Mention of company or trade names is for description only and does not imply endorsement by the USDA. The USDA is an equal opportunity provider and employer.

The authors are Garey A. Fox, Editor-in-Chief of ASABE Journals, Professor and Head, Department of Biological and Agricultural Engineering, North Carolina State University, Raleigh, North Carolina; Kyle R. Douglas-Mankin, ASABE Community Editor for Natural Resources and Environmental Systems (NRES), Research Leader and Research Agricultural Engineer, USDA-ARS Water Management and Systems Research Unit, Fort Collins, Colorado; Kasiviswanathan Muthukumarappan, ASABE Community Editor for Energy Systems (ES), Distinguished Professor and Graduate Coordinator, Department of Agricultural and Biosystems Engineering, South Dakota State University, Brookings, South Dakota; Jun Zhu, ASABE Community Editor for Plant, Animal, and Facility Systems (PAFS), Professor, Department of Biological and Agricultural Engineering, University of Arkansas, Fayetteville, Arkansas; Joseph C. Walker, Director of Publications, American Society of Agricultural and Biological Engineers, St. Joseph, Michigan. Corresponding author: Garey Fox, 104 Weaver Administration, Raleigh, NC 27695; phone: 919-515-6700; e-mail: gafox2@ncsu.edu.
To cope with the rapidly changing world of research publishing, graduate students, postdoctoral research scholars, and young researchers need to be informed about the publication process. They also need to determine the quality of a journal based on a variety of metrics and the strength of its peer-review process. Researchers now have a wide range of journals to choose from in submitting their work for publication, and each journal has its own advantages and disadvantages.

The objective of this perspective article is to present some suggestions for navigating the publication process in peerreviewed journals. This article should be read with the following points in mind. First, the peer-review process should improve an author's contribution to the scientific and engineering literature. Second, prospective authors should select a journal based on its actual readership and the article's likelihood to be cited, not just the journal's IF. A journal should reach those who are most likely to read and cite the research, and the IF does not necessarily reflect an article's research impact. Next, there are always improvements that can be made to a manuscript, even after acceptance, so authors should solicit useful advice before and during the review process. Finally, persistence is the key to success in publishing scientific and engineering research, and good manuscripts will eventually be published.

\section{The Process toward Publication}

The process toward publication often starts with submission of an abstract for an oral or poster presentation at a conference. Presentation at a conference may require submission of a proceedings paper. In any case, authors should always attempt to develop a proceedings paper to accompany their presentation, as this effort will help them communicate their research during the presentation and progress toward publication of their research. With that advice comes a word of caution: in some cases, the conference sponsor claims copyright on the proceedings papers. Therefore, significant differences may be required between the original paper and 
Table 1. Article types that are published in ASABE journals (approved in 2019).

\begin{tabular}{ccl}
\hline Type & Length & \multicolumn{1}{c}{ Description } \\
\hline Research article & $\begin{array}{c}12,000 \text { words, or } \\
\text { about } 25 \text { formatted pages }\end{array}$ & $\begin{array}{l}\text { Original, important contribution to the research, education, or design literature that is of in- } \\
\text { terest to the profession of agricultural and biological engineering. }\end{array}$ \\
\hline Research brief & $\begin{array}{c}5,000 \text { words, or } \\
\text { about } 8 \text { formatted pages }\end{array}$ & $\begin{array}{l}\text { Succinct, original, practical, or preliminary contribution to the research, education, outreach, } \\
\text { or design literature that is of interest to the profession, typically with a limited scope. }\end{array}$ \\
\hline Review article & $\begin{array}{l}12,000 \text { words, or } \\
\text { about } 25 \text { formatted pages }\end{array}$ & $\begin{array}{l}\text { Critical review, synthesis, and insightfully organization of recent literature on a topic of in- } \\
\text { terest to the profession of agricultural and biological engineering. }\end{array}$ \\
\hline Frontier article & $\begin{array}{c}4,000 \text { words, or } \\
\text { about } 8 \text { formatted pages, } \\
\text { no abstract, limited references }\end{array}$ & $\begin{array}{l}\text { Review, new results (if possible), and vision of recent engineering, science, or educational } \\
\text { advances at the forefront of one or several disciplines within the profession. }\end{array}$ \\
\hline Perspective & $\begin{array}{l}1,000 \text { to } 4,000 \text { words, or } \\
\text { about } 1 \text { to } 4 \text { formatted pages, } \\
\text { no abstract, limited references }\end{array}$ & $\begin{array}{l}\text { Thought-provoking, focused personal review, balanced viewpoint, or discussion of the inter- } \\
\text { face between agricultural, food, and biological engineering and policy, social, or global is- } \\
\text { sues of pressing importance to the profession and written for a broad readership. Also in- } \\
\text { cludes synthesis and interpretation of a recent conference, workshop, or symposium. }\end{array}$ \\
\hline
\end{tabular}

the manuscript that is later submitted for publication in a journal. At a minimum, the journal manuscript needs to have more detailed results and an extended discussion of the results.

Authors who present papers at ASABE conferences are strongly encouraged to submit their papers for publication in one of the ASABE journals (Transactions of the ASABE, Applied Engineering in Agriculture, and the Journal of Agricultural Safety and Health). ASABE does not consider these conference papers to have prior publication status, and authors are free to submit their ASABE papers for journal publication. However, additional effort must be invested in preparing such manuscripts, including the feedback and insights gained from the author's presentation at the conference.

Journals often publish several types of articles, so authors should not constrain themselves to research articles. Table 1 describes the types of articles that are currently published in ASABE journals. Review articles and articles that are part of a special collection focus on a current topic and tend to be widely cited. Ideas for review articles and special collections typically arise from discussions with colleagues at technical committee meetings, which is an advantage for researchers who are involved in their professional society at the committee level. Research published as part of a special collection can reach a wider audience than a single article. In completing their thesis or dissertation, students should make the literature review as comprehensive as possible because literature reviews can be developed into review articles. Prospective authors can also convert the background and objectives from a recently funded grant proposal into a review article that highlights the need for future research. In many cases, submission of a manuscript for publication other than as a research article or research brief may require approval from the journal's editorial board. Before submitting a manuscript, always review the journal's website for specific requirements.

\section{Where to PUblish}

There are many journals, and the number continues to grow. Prospective authors should select a journal that can maximize the impact of their research. Primary considerations should include: (1) the journal's readership, coverage, and relevance; (2) the databases in which the journal is indexed; (3) the IF and other metrics; (4) the typical review time; (5) the page charges and other fees; and (6) the quality of the review process. Consider all these factors, not just the
IF. Journals with a higher IF may not reach the target audience or provide an appropriate, high-quality review. The journal's IF for a specific year is calculated as follows (example shown for 2018):

$$
\mathrm{IF}_{2018}=\frac{\text { Citations in } 2018 \text { to items in } 2016 \text { and } 2017}{\text { Number of citable items in } 2016 \text { and } 2017}
$$

While the IF may be a useful metric for assessing the impact of the entire journal, it is not relevant for assessing the impact of an individual article. More specifically, the IF assumes that all the articles in a journal have the same scientific merit, as measured by the journal's IF (Brito and Rodríguez-Navarro, 2019). There have been numerous calls to move away from the use of IF because most published articles garner fewer citations than indicated by the journal's IF, and a few highly cited articles can easily influence this metric (Callaway, 2016). However, the IF remains an easyto-use, predictive method to assess journal quality. Therefore, prospective authors need to be aware of its perceived value and widespread use.

As of 2018, the IF for Transactions of the ASABE was 1.153. Therefore, based on the IF, this journal ranks in the middle of its category, although the total citations of its published articles are almost twice the number for many of its comparison journals. Citation longevity is another important advantage of journals published by professional societies such as ASABE. Articles published in ASABE journals tend to be cited over multiple decades (e.g., the cited half-life for Transactions of the ASABE is more than 14 years, according to the most recent reports), so an ASABE article can make a long-term contribution to an author's field of research. Instead of predicting impact based on a journal's IF, the real impact of a research article should be quantified based on the number of citations to the article over time. In engineering, that window of citation analysis should be greater than the two-year to five-year period used for determining the IF.

The ASABE journals are a repository of the engineering contributions made by ASABE members and non-members in a wide range of disciplines. ASABE arranges those many disciplines into the following technical communities: applied science and engineering (ASE); education, outreach, and professional development (EOPD); energy systems (ES); ergonomics, safety, and health (ESH); information technology, sensors, and control systems (ITSC); machinery systems (MS); natural resources and environmental systems (NRES); plant, animal, and facility systems (PAFS); and 
processing systems (PRS). In addition, with advances in databases and search engines, it is easy to find articles on a specific topic. The ASABE journals are currently indexed by the following databases: AGRICOLA, CAB Abstracts, EBSCO A to Z Service, EBSCO Discovery Service, EI Compendex, Google and Google Scholar, Meta, OCLC WorldCat Discovery Services, Scopus, Summon, and Web of Science.

Many authors use platforms such as ResearchGate and Google Scholar to share their research publications and update colleagues on specific projects. Those platforms are an excellent way to increase the visibility of publications and promote research programs. For example, Google Scholar reports an author's $h$-index (i.e., the number of publications for which an author has been cited at least that same number of times) and provides links to all the articles that cite a specific publication. Google Scholar also connects directly to ASABE's database of publications. ASABE copyright policy prohibits authors from uploading their ASABE publications directly to ResearchGate or other third-party platforms; however, those platforms are useful for sending e-mails with individual publications attached. Authors can also post copies of their ASABE publications on their own websites and on their employer's websites.

The time required for the peer-review process is an important consideration in selecting a journal. Although review times depend on many factors, and they vary widely among journals and among manuscripts within a journal, journals often have targets for the timeliness of review. ASABE journals have a goal of returning a first decision to the author within 60 days of manuscript submission. In many cases, the review proceeds much more quickly. Delays can occur, especially when appropriate reviewers are difficult to locate for a particular manuscript. Therefore, prospective authors should volunteer to participate in the peer-review process by reviewing manuscripts in their area of expertise. Ideally, because two or three reviewers, on average, evaluate each manuscript, authors should review two or three manuscripts for each manuscript that they submit.

Unfortunately, the quality of the peer-review process is sometimes not considered in selecting a journal. An overemphasis on rapid publication (for example, to increase the number of publications required for professional promotion) may draw researchers to journals with short review times without consideration of the review quality. A high-quality review ensures a high-quality article. Is a publication without a high-quality review really worth it when considering the potential negative impact on the author's reputation, if a reader later discovers an error in the procedures or the analysis? ASABE journals have a long-standing reputation for fair, thoughtful, and constructive reviews.

Journals can charge authors various fees for publishing their manuscripts, often as a cost per published page, also called an author page charge (APC). Journals without APCs derive their income by other means, such as subscriptions or individual article sales. APCs can range from $\$ 50$ to $\$ 400$ per printed page, either for all pages or for pages that exceed a certain limit. Authors may pay reduced APCs for publishing in a special collection or for an invited review article. Almost all journals, including ASABE journals, now allow authors to publish their articles as open access, so that the article is available to the general public. In fact, many journals are completely open access.

Authors should make sure that they are submitting their manuscript to a relevant journal. If the manuscript is based on a small-scale study of local significance, then a high-profile, international journal may be less suitable than a smaller, more focused journal. If a specific field has highly active researchers, then prospective authors should submit to a journal that is highly visible to those researchers.

Finally, in selecting an appropriate journal, authors should consider the journals that are most commonly cited in their own research. Including several references from the selected journal can demonstrate the suitability of a manuscript to the journal's editors and reviewers. Conversely, if an author seeks to publish several manuscripts on a similar topic, submitting the manuscripts to different journals may be beneficial for reaching a broader and more diverse audience.

\section{ORganizing THE MANUSCRIPT}

Journal articles use a formal structure that allows efficient communication of the research process and findings. Most articles begin with an abstract that briefly conveys the key points of the research in about 250 to 300 words. The abstract should include one or two sentences that introduce the research topic, one sentence for the objectives, one or two sentences for the methods, two or three sentences for the results, and, importantly, one sentence for the broader implications of the study. A common mistake is to have too much introduction and methods, too few results, and no statement of the broader impact. A well-written abstract is critical because the abstract is widely indexed, and it is often the only part of the article that is widely read.

The body of the manuscript elaborates on each element of the research, as presented in the abstract. The introduction provides context, cites relevant literature, and demonstrates the need for the study. Do not start the introduction too broadly; the reader should understand the topic by the end of the first paragraph. Provide enough background for the reader to understand what is already known about the topic and that the need for the study is clear. In the methods section, explain the materials, tools, and processes used in the study, including the study location or environment, the handling of the materials, and the data sources, data processing, and statistical analyses, with enough detail to be unambiguous and complete and with the goal of replicability. Do not elaborate on common research or statistical methods; instead, include citations that provide those details. State the results clearly and directly with reference to the accompanying tables and figures. Highlight important results in the tables and figures without simply restating what the reader can easily see. Do not reiterate the methods as a lead-in to the results. Most importantly, interpret and discuss the results; do not make the reader guess what the results mean or how to interpret them. Conclude the body of the manuscript by briefly discussing the implications of the research for the scientific and engineering community.

Finally, the references list at the end of the manuscript should be formatted correctly, according to journal's pre- 
ferred style. Cross-check the reference citations in the body of the manuscript with the references list to ensure that they match.

\section{Prior TO SUbMission}

Several factors within the author's control can help improve the peer-review process for a manuscript. Use clear writing and good grammar. If you are not a native English speaker, ask a colleague to review the manuscript before submission. Closely follow the journal's guidelines regarding manuscript format. Bad writing and incorrect formatting can lead to an immediate rejection. The journal's guidelines may specify the maximum length of a manuscript for each article type (table 1), as well as the length of the abstract, the use of keywords, labeling of sections within the manuscript, the reference style, and the appearance of the text, tables, figures, and other elements. Some journals require that authors use a standard manuscript template, while other journals are moving toward flexible formatting for manuscript submission, as long as the manuscript is consistent in style, clearly organized, and well written. In such cases, a templated manuscript may be required later, upon submission of the revised manuscript or at the time of acceptance. An advantage of manuscript templates, such as the templates used for ASABE journals, is that they decrease the review time by providing a consistently formatted document for the reviewers, and they decrease the editing effort required for publication. Many journals may also require highlights (short bulleted points that summarize the research) or a graphical abstract (an illustration that summarizes the research). Graphical abstracts are typically made available online to encourage readership.

Some common mistakes that authors make when submitting their first version of a manuscript are outlined in table 2. In general, scientific and engineering writing is formal, with no contractions (e.g., use "are not" instead of "aren't"), vague quantities (e.g., "a few days", "really big"), or other figures of speech. Most importantly, good writing is succinct. This is especially true when publishing in a scientific or engineering journal because a highly technical vocabulary can cause sentences to expand in length and complexity. Go through each sentence of the manuscript and determine if there is a way to reduce the number of words. In particular, avoid passive redundancy, such as "There were three key reasons that were found for the resulting outcome" (say instead: "We found three reasons for the outcome"), and avoid needless abstraction, such as "In terms of course presentation platform, we employed a classroom environment" (say instead: "We presented the course in a classroom"). In general, avoid long sentences. A manuscript is easier to read with shorter, simpler sentences. Typically, simpler wording and shorter sentences will significantly improve the quality of the manuscript. Finally, read the manuscript out loud. If a sentence is difficult to read or does not sound right, then it probably needs further improvement.

To save space, define all variables and abbreviations at their first appearance in the manuscript. The variables and abbreviations can then be used without further definition in the rest of the manuscript. If the manuscript contains equations, create the equations using Equation Editor or other equation software, and number the equations consecutively in the text. Be aware of significant digits; there is an important difference between $1.00 \mathrm{~m}$ and $1.000 \mathrm{~m}$. Consult the journal's guidelines regarding the use of variables, abbreviations, and Greek letters.

For a manuscript with multiple authors, the lead author's responsibility is to ensure that all co-authors have read and contributed to the manuscript. Determining authorship can be a subject of much debate, and authorship can have important academic, professional, and financial implications. The project collaborators should reach an understanding about authorship before the manuscript is submitted. As a guide, the International Committee of Medical Journal Editors (ICMJE, 2019) recommends defining authorship based on four criteria:

Table 2. Common mistakes made by authors in the first version of a submitted manuscript.

\begin{tabular}{|c|c|}
\hline Mistake & Recommendation \\
\hline $\begin{array}{l}\text { The manuscript contains errors in } \\
\text { grammar and word usage. }\end{array}$ & $\begin{array}{l}\text { Write correctly. If English is not your first language, ask a native English speaker to review the manuscript, } \\
\text { or hire an editing service. A poorly written manuscript can be rejected immediately. }\end{array}$ \\
\hline $\begin{array}{l}\text { The keywords simply repeat the } \\
\text { terms in the manuscript title. }\end{array}$ & $\begin{array}{l}\text { Include keywords that are not included in the manuscript title and that will be useful for on-line searches on } \\
\text { the topic. Journal publishers often have lists of recommended keywords. }\end{array}$ \\
\hline $\begin{array}{l}\text { The terminology is inconsistent, and } \\
\text { the sentence structure is inappropriate } \\
\text { or overly complicated. }\end{array}$ & $\begin{array}{l}\text { Use a single consistent word, phrase, or acronym to identify each concept, and use it throughout, even if it } \\
\text { seems redundant. Use similar wording to express similar concepts. Use sentence structure that allows the } \\
\text { reader to scan the meaning within a sentence and compare meanings among sentences. }\end{array}$ \\
\hline $\begin{array}{l}\text { The introduction does not lead to } \\
\text { a statement of the objective. }\end{array}$ & $\begin{array}{l}\text { The introduction is a brief description of previous, relevant research. Not all the research reviewed for the } \\
\text { study needs to be included. Emphasize what remains unknown or problematic. Include a detailed statement } \\
\text { of the research question, objective, or hypothesis at the end of the introduction. }\end{array}$ \\
\hline The object & $\begin{array}{l}\text { Include a concise and clear objective statement at the end of the introduction that explicitly identifies the } \\
\text { goal of the research. The methods and results must directly address this objective. }\end{array}$ \\
\hline $\begin{array}{l}\text { The methods and the results are } \\
\text { not clearly distinguished. }\end{array}$ & $\begin{array}{l}\text { Do not mix the methods and the results. Within the methods section, use subheadings to outline the proce- } \\
\text { dures used, and include corresponding subheadings in the results section. }\end{array}$ \\
\hline $\begin{array}{l}\text { The results of the study are not } \\
\text { adequately discussed. }\end{array}$ & $\begin{array}{l}\text { Provide an extensive discussion of the results, compare the results with previously reported studies, and } \\
\text { comment on the differences, if any. Do not simply write a project report on your own study. }\end{array}$ \\
\hline $\begin{array}{l}\text { The tables and figures are not clearly } \\
\text { labeled or mentioned in the text. }\end{array}$ & $\begin{array}{l}\text { All tables and figures must be mentioned in the text and numbered consecutively. The tables and figures } \\
\text { should have detailed captions that allow them to stand on their own, apart from the text. }\end{array}$ \\
\hline A meaningful conclusion is lacking. & $\begin{array}{l}\text { Do not simply summarize the study. Instead, discuss the implications of the research for the scientific and } \\
\text { engineering community. }\end{array}$ \\
\hline $\begin{array}{l}\text { The references list is not consistent } \\
\text { with the citations in the text. }\end{array}$ & $\begin{array}{l}\text { All references cited in the text must appear in the references list, and the references list must only include } \\
\text { the references that are cited in the text. }\end{array}$ \\
\hline $\begin{array}{l}\text { The references are not formatted } \\
\text { in the journal's preferred style. }\end{array}$ & $\begin{array}{l}\text { Use the journal's preferred style for author names, publication titles, volume/issue/page numbers, and other } \\
\text { reference information. When available, include DOI numbers in the references. }\end{array}$ \\
\hline
\end{tabular}


- "Substantial contributions to the conception or design of the work; or the acquisition, analysis, or interpretation of data for the work;

- Drafting the work or revising it critically for important intellectual content;

- Final approval of the version to be published;

- Agreement to be accountable for all aspects of the work in ensuring that questions related to the accuracy or integrity of any part of the work are appropriately investigated and resolved."

The ICMJE suggests that authors should acknowledge, but not grant authorship to, individuals who do not meet all four of the above criteria. While ASABE does not have a specific policy on determining authorship, reaching an agreement on authorship early in a research project will avoid delays and possible conflicts when submitting the manuscript.

All journal publishers now use on-line systems for manuscript submission. Because these systems create a database, prospective authors typically must enter information about their manuscript, as well as the manuscript files. This information includes the manuscript title, author names and contact information, the abstract and keywords as separate elements, and possibly information about the manuscript content (e.g., the number of figures, word count, and supplementary material).

Authors are also required to suggest three to five reviewers. Suggested reviewers should be individuals who do not have a conflict of interest and who can provide a thorough, informed review of the manuscript. Because the peer-review process is about improving the scientific and engineering literature, authors should suggest highly qualified reviewers for their manuscript. Authors should not suggest individuals whom they believe will give an easy review; they should identify individuals who will improve the research. If highly qualified individuals do not review the manuscript during the peer-review process, then they will likely critique the article after publication, when corrections are no longer possible. Of course, there may be cases in which specific individuals will not provide an unbiased review. Therefore, authors can also suggest individuals to exclude from the review process. Ideally, the journal's editorial board will monitor the quality of the review process to ensure that the assigned reviewers are providing fair evaluations of all manuscripts.

\section{The Peer-Review Process}

For simplicity, we will restrict this discussion of the peerreview process to ASABE journals, although the process is similar for most reputable journals. Upon submission of a manuscript, the journal's editorial staff verifies that the manuscript complies with the requirements in the journal's guide for authors. This process typically requires one to three days for ASABE journals. The manuscript is then assigned a manuscript number, or it may be returned to the author if it does not comply with the submission guidelines. The numbered manuscript is then sent to a community editor (CE), who gives the manuscript a quick assessment of the writing and technical quality, ensures its fit within the scope of the journal, analyzes the results of the similarity assessment (i.e., plagiarism detection software), and reviews any other information provided by the author. This process typically requires two to seven days. High-quality manuscripts move through this process quickly; however, the CE can reject a manuscript if it is poorly written or outside the scope of the journal.

After the initial assessment of the manuscript, the $\mathrm{CE}$ assigns an associate editor (AE), who also assesses the manuscript. The AE's role is to make a recommendation on whether or not the manuscript should be published; if so, the $\mathrm{AE}$ helps guide the manuscript through the publication process. If the $\mathrm{AE}$ does not believe that the manuscript can be made suitable for publication, the AE will recommend immediate rejection to avoid investing time and effort in the peer-review process.

After assessing the manuscript, the $\mathrm{AE}$ has three options: submit a rejection recommendation to the $\mathrm{CE}$, recommend returning the manuscript to the author for revision before peer review, or begin the process of selecting reviewers. AEs typically select one or two reviewers from the author's list of suggested reviewers, but they are cautious about selecting reviewers who may have a conflict of interest. A logical source of reviewers who were not recommended by the author is the manuscript's references list. ASABE's goal is to select reviewers within 21 days of manuscript submission. The difficulty in finding qualified, willing, and available reviewers, who are all volunteers, is the most common source of delay. In most cases, ASABE's goal is to receive three reviews for each manuscript; however, the AE may be able to make an informed recommendation with fewer reviews. There are also cases in which the AE may need more than three reviews to make an informed recommendation.

After the AE has selected reviewers who have agreed to review the manuscript, the reviewers typically have 28 days to complete their evaluation. The reviewers should proceed in a timely manner. They should not wait until shortly before the review is due to begin their evaluation. ASABE prefers that reviewers perform an immediate read-through of the manuscript upon receipt, to begin thinking about the research. By agreeing to review a manuscript, the reviewers have agreed to participate in the improvement of that manuscript toward publication. Reviewers should spend significant time evaluating the manuscript, and they should be prepared to evaluate the manuscript again after revision.

Each reviewer makes one the following recommendations on the manuscript: (1) publish as is; (2) publish with minor revisions and no need for further review; (3) the manuscript is publishable, but it needs major revision and additional review; or (4) do not publish. When a manuscript is reviewed by qualified experts, such reviewers always find some way in which the manuscript can be improved. Therefore, very few manuscripts receive a recommendation to "publish as is" after the first review. After all of the reviewers have submitted their comments and recommendations to the $\mathrm{AE}$, the $\mathrm{AE}$ re-assesses the manuscript, considering the reviewer comments, and makes a recommendation to the $\mathrm{CE}$ regarding publication of the manuscript.

Considering the AE's recommendation, the $\mathrm{CE}$ makes a formal decision on the manuscript and informs the author. If the manuscript is rejected after the peer-review process, the 
author should consider the reviewers' comments and make appropriate corrections. Rejection is not necessarily final. It may be that the reviewers did not understand the research because the author did not communicate the objectives, methods, results, or conclusions clearly enough. The author can use the reviewer comments to improve the manuscript and then choose to re-submit the manuscript to the same journal or to a different journal. Authors can also challenge the CE's decision by contacting the journal's editor-in-chief; however, they should pursue this route only with explicit evidence of misevaluation of the manuscript.

If the manuscript is accepted but requires revision, the author must address the reviewer comments in a point-by-point response letter. The author may also be asked to submit a revised version of the manuscript that tracks all the changes. In the response letter, which is submitted with the revised manuscript, the author should address each reviewer comment, including the line numbers where changes were made in the manuscript. Every reviewer comment that is acknowledged in the response letter should be reflected in the revised manuscript. To move the manuscript toward publication, the author should make the revised manuscript as correct as possible. When authors disagree with a reviewer comment, they should provide a rationale for not making the suggested correction. Most of all, the author should maintain an optimistic outlook; every reviewer comment can improve the manuscript for publication.

When the author resubmits the revised manuscript, two versions of the manuscript (a tracked-changes copy and a clean copy) and the author's response letter are routed back through the review process. The journal's editorial staff again checks the manuscript for compliance with the journal guidelines, and the revised manuscript is forwarded to the AE, who reviews the author's response letter and decides how to proceed. If the suggested changes were minor and have been fully addressed, the AE may recommend publishing the manuscript without additional review. If the changes were more significant, the AE will likely forward the manuscript to the original reviewers. The AE can also invite new reviewers to participate in the review process but will likely do so only when none or only one of the original reviewers are available. If new reviewers are needed, the best practice for AEs is to invite colleagues who can review the manuscript promptly. If the AE believes that the author did not adequately address the reviewer comments on the original manuscript, then a recommendation to reject the manuscript is likely; otherwise, the re-review process can become cyclical. To avoid multiple reviews, authors must do their best to address all the comments from the AE and the reviewers.

Authors can track the review process through the journal's on-line manuscript submission system. These systems vary among journal publishers, and different systems use different terminology; however, in general, authors should be able to track the progress of their manuscript. Knowing the journal's performance goals for the review process can provide guidance on when to contact the journal staff about the status of a manuscript (i.e., when the process is late or overdue). However, good reviews take time, and they are worth waiting for. Do not ask for an update too soon, nor ask for too many updates, but hold the journal to its own performance goals. The journal staff will be honest with authors who have honest concerns about delays in the process. Similarly, when authors have received the reviewer comments and are revising their manuscript for resubmission, they should hold themselves to a goal of returning the revised manuscript within 14 days if the comments are minor, and within 30 days if the comments are more significant.

\section{AFTER ACCEPTANCE}

When the manuscript has been accepted, the author can celebrate that the research will be published! Immediately upon acceptance, most journals publish manuscripts on-line as "in press" or "accepted". The accepted manuscript is also assigned a unique DOI number to provide a permanent link to its location on the internet. To prepare the manuscript for publication, the journal staff edits and typesets the manuscript and sends a proof copy to the author to review. Highquality editing is invaluable for polishing a manuscript and strengthening its contribution to the literature. The quality of the editing process varies significantly among journals. ASABE's editorial staff invests significant time and energy in every manuscript, performing a detailed edit and ensuring that the manuscript conforms with all the requirements for on-line indexing, so that the published article will be available to the widest possible audience.

When authors receive the pre-publication proof copy, they are typically given a week to review it and make any necessary corrections. Authors need to review the proof copy carefully, as the editing process and auto-correction algorithms may have made changes that alter the intended meaning. Do not be afraid to make minor corrections. Every detail counts, and no changes can be made after the proof process. Authors should also verify the appearance of all equations, tables, and figures. If the image resolution of a figure is not appropriate for printing, ASABE's editorial staff may request a higher-quality image. A useful guideline is to ensure that the fonts used in the figures are no smaller than the smallest font in the text. The author many also need to respond to questions from the editorial staff regarding missing elements or inconsistencies in the accepted manuscript.

After making any necessary corrections, the author returns the corrected proof copy, and ASABE publishes the manuscript, usually in the upcoming issue of the journal. For many journals that have a large backlog of manuscripts, publication may be delayed for as much as a year after acceptance. That is not the case with ASABE journals. Upon publication, the author's manuscript officially becomes a journal article, a peer-reviewed contribution to the professional literature, and the author can celebrate again!

\section{Professional Recognition}

Publishing in the journals of a professional engineering society such as ASABE provides additional opportunities for recognizing an author's research as influential to the profession. For example, ASABE annually recognizes 5\% of the articles that are published in its three peer-reviewed journals with Superior Paper Awards. These awards are based on the 
article's timeliness, fundamental value, originality, and benefit to the profession. During the peer-review process, AEs can recommend that an outstanding manuscript be considered for a Superior Paper Award.

In reviewing some of the Superior Paper Award winners for 2019 (e.g., Ban et al., 2018; Her and Heatwole, 2018; Jones et al., 2018; Li et al., 2018; Teske et al., 2018; Zhou et al., 2018), it is readily apparent that the quality of the writing and the overall presentation of the research are extremely important. These articles are ideal examples of avoiding the common mistakes listed in table 2; manuscripts that require major revision due to those common mistakes are not likely to be considered for a Superior Paper Award. An impressive article does not have to be an extensive research publication, as one of the 2019 award-winning articles (Ban et al., 2018) is a research brief. Finally, these award-winning articles include well-designed figures that effectively illustrate the research, as well as descriptive subheadings that help readers navigate through the text and quickly grasp the content and organization.

A manuscript that is well written, well organized, and well referenced will result in a faster peer-review process, it will substantially increase the chances that the published article will be nominated for special recognition, and it will make a useful contribution to the literature of the profession.

\section{REFERENCES}

Ban, G.-H., Rungraeng, N., Li, Y., \& Jun, S. (2018). Nanoporous stainless steel surfaces for anti-bacterial adhesion performances. Trans. ASABE, 61(3), 1175-1179. https://doi.org/10.13031/trans.12677

Brito, R., \& Rodríguez-Navarro, A. (2019). Evaluating research and researchers by the journal impact factor: Is it better than coin flipping? J. Informetrics, 13(1), 314-324. https://doi.org/10.1016/j.joi.2019.01.009

Callaway, E. (2016). Beat it, impact factor! Publishing elite turns against controversial metric. Nature News, 535(7611), 210-211. https://doi.org/10.1038/nature.2016.20224

Her, Y., \& Heatwole, C. (2018). Identification of hydrologically sensitive areas considering watershed process dynamics. Trans. $A S A B E, 61(6), 1891-1906$. https://doi.org/10.13031/trans.12792

ICMJE. (2019). Defining the role of authors and contributors. International Committee of Medical Journal Editors. Retrieved from http://www.icmje.org/recommendations/browse/roles-andresponsibilities/defining-the-role-of-authors-andcontributors.html

Jones, D. S., Searcy, S. W., \& Eaton, L. M. (2018). Assessment of perennial grass inventories predicted in the billion-ton studies. Trans. ASABE, 61(2), 331-340. https://doi.org/10.13031/trans.12505

Li, R., Lu, Y., \& Lu, R. (2018). Structured illumination reflectance imaging for enhanced detection of subsurface tissue bruising in apples. Trans. ASABE, 61(3), 809-819. https://doi.org/10.13031/trans.12243

Teske, M. E., Wachspress, D. A., \& Thistle, H. W. (2018). Prediction of aerial spray release from UAVs. Trans. ASABE, 61(3), 909-918. https://doi.org/10.13031/trans.12701

Zhou, Y., Dong, H., Xin, H., Zhu, Z., Huang, W., \& Wang, Y. (2018). Carbon footprint assessment of a large-scale pig production system in northern China: A case study. Trans. ASABE, 61(3), 1121-1131. https://doi.org/10.13031/trans.12805 